\title{
Analgesic, Anti-Inflammatory, and Antioxidant Activities of Byrsonima duckeana W. R. Anderson (Malpighiaceae)
}

\author{
Maria Christina dos Santos Verdam, ${ }^{1,2}$ Fernanda Guilhon-Simplicio, ${ }^{3}$ \\ Kleyton Cardoso de Andrade, ${ }^{3}$ Karina Lorena Meira Fernandes, ${ }^{4}$ \\ Tallita Marques Machado, ${ }^{3}$ Felipe Moura Araújo da Silva, ${ }^{5}$ Mayane Pereira de Souza, \\ Hector Henrique Ferreira Koolen, ${ }^{6}$ Cristiane da Silva Paula, \\ Beatriz Cristina Konopatzki Hirota, ${ }^{1}$ Vinícius Bednarczuk de Oliveira, ${ }^{1}$ \\ Cristina Mayumi Sasaki Miyazaki, ${ }^{1}$ Milena Kalegari, ${ }^{1}$ Marilis Dallarmi Miguel, ${ }^{1}$ \\ Patricia Maria Stuelp-Campelo, ${ }^{4}$ and Obdulio Gomes Miguel ${ }^{1}$
}

\author{
${ }^{1}$ Department of Pharmacy, Federal University of Paraná, Curitiba, PR, Brazil \\ ${ }^{2}$ Faculty of Pharmacy, Federal University of Rio de Janeiro, Rio de Janeiro, RJ, Brazil \\ ${ }^{3}$ Faculty of Pharmaceutical Sciences, Federal University of Amazonas, Manaus, AM, Brazil \\ ${ }^{4}$ Center of Biological and Health Sciences, Pontifical Catholic University of Paraná, Curitiba, PR, Brazil \\ ${ }^{5}$ Department of Chemistry, Federal University of Amazonas, Manaus, AM, Brazil \\ ${ }^{6}$ DeMpSter Mass Spectrometry Group, Amazonas State University, Manaus, AM, Brazil
}

Correspondence should be addressed to Fernanda Guilhon-Simplicio; guilhon_simplicio@ufam.edu.br

Received 22 December 2016; Accepted 9 February 2017; Published 6 March 2017

Academic Editor: Valdir Cechinel Filho

\begin{abstract}
Copyright (C) 2017 Maria Christina dos Santos Verdam et al. This is an open access article distributed under the Creative Commons Attribution License, which permits unrestricted use, distribution, and reproduction in any medium, provided the original work is properly cited.
\end{abstract}

Background. Byrsonima is a promising neotropical genus, rich in flavonoids and triterpenes, with several proven pharmacological properties. Nevertheless, Byrsonima duckeana W. R. Anderson is an Amazonian species almost not studied. Objective. To assess the antioxidant, anti-inflammatory, and analgesic activities of Byrsonima duckeana leaves. Materials and Methods. We analyzed an ethanol extract and its fractions for polyphenol content and UHPLC-MS/MS, phosphomolybdenum, DPPH, TBARS antioxidant tests, formalin-induced pain, carrageenan-induced peritonitis, acetic acid-induced abdominal writhings, and hot plate assays. Results. All the samples showed high polyphenol content and antioxidant capacity in the phosphomolybdenum, DPPH, and TBARS tests. We identified ethyl gallate, quinic acid, gallic acid, catechin, epicatechin, quercetrin, and quercetin in the samples. B. duckeana was able to reduce leukocyte migration in the carrageenan-induced peritonitis by $43 \%$ and the licking time in the formalin test by $57 \%$. In the acetic acid-induced writhing test, the chloroform (FCL) and ethyl acetate (FEA) fractions were the most active samples. FEA was selected for the hot plate test, where all the dosages tested $\left(5,50\right.$, and $\left.200 \mathrm{mg} \cdot \mathrm{kg}^{-1}\right)$ showed significant analgesic activity. Conclusion. B. duckeana has interesting analgesic and antioxidant activities, due to its high phenolic content, especially phenolic acids.

\section{Introduction}

Inflammation is a response of immune system that activates many enzymatic and cellular processes to protect the body from all kinds of trauma [1]. This process is associated with pain [2], which is caused by the stimulation of afferent nervous fibers by inflammatory chemical mediators, whose primary function is to protect the organism [3]. Despite the importance of the inflammatory process in providing protection, pain is one of the most frequent factors that motivates individuals to seek medical help and is a cause of low productivity in the workplace, absence due to sickness, and early retirement [4]. 
Beside inflammatory pain, other usual kinds of pain are nociceptive and neuropathic. Although they have separate mechanisms, both nociceptive and neuropathic types of pain share physiological aspects with the inflammatory pain. The first is mostly caused by the sensitization of primary nociceptive neurons through direct action of inflammatory mediators due to tissue damage [5]. Nociceptive pain is characterized by sensitization of the nerve fibers by receptors and ionic channels that are sensitive to heat, cold, and protons. Neuropathic pain is caused by a lesion or disease affecting the somatosensory nervous system [6].

The Byrsonima genus, a member of the Malpighiaceae family, has more than 100 described species [7], distributed through neotropical regions [8]. Species of this genus have attracted the interest of researchers by their antimicrobial activity against gram-positive, gram-negative, and enteric bacteria, along with mycobacteria, protozoa, and fungi. Other biological activities, such as spasmogenic, immunostimulatory, anti-inflammatory, antihemorrhagic, antihyperglycemic, antihyperlipidemic, antiulcer, antidiarrheal, and antioxidant activities, were also investigated in different species [9].

Byrsonima duckeana W.R. Anderson is a tree found in the Brazilian Amazon rainforest, about which we previously reported promising cytotoxicity on colon cancer cells [10]. However, its pharmacological and chemical potential are still underexplored, since we already observed in vivo activities of other Amazonian Byrsonima species, Byrsonima japurensis, that has promising anti-inflammatory, analgesic, and antioxidant activities, corroborating its popular use [11]. Thereby, this study evaluated the chemical composition and the antioxidant, anti-inflammatory, and analgesic activities of the ethanolic extract and its fractions from the leaves of $B$. duckeana, in order to better evaluate its in vivo pharmacological potential.

\section{Materials and Methods}

2.1. Plant Material. The leaves from a flowering plant of Byrsonima duckeana were collected in November 10, 2010, in the Adolpho Ducke Reserve, Manaus, Amazonas State, Brazil, from a specimen previously catalogued during the "Flora da Reserva Ducke” project [12], when a voucher (\#179696) was deposited in the Herbarium of the National Institute of Research in the Amazon (INPA). The Institute Chico Mendes for Biodiversity Conservation provided authorization (\#41553-1) from the Brazilian Ministry of Environment for the plant collection.

2.2. Preparation and Fractionation of Crude Extract. Leaves from $B$. duckeana were dried at $40^{\circ} \mathrm{C}$ in a convection oven. The plant material was crushed and submitted to extraction in a Soxhlet apparatus. The material was extracted with ethanol until exhaustion, yielding a crude extract named EEB, used in the tests. An aliquot of EBB was suspended in ethanol and partitioned with hexane, chloroform, and ethyl acetate, three times each, affording fractions FHX, FCL, and FEA, respectively.
2.3. Determination of Total Phenolics. The extract and its fractions were submitted to the Folin-Ciocalteu colorimetric method for determination of their phenolic content by a previously described methodology [13]. The analysis was performed in triplicate, and the results were expressed in $\mathrm{mg}$ of gallic acid equivalents (GAE. $100 \mathrm{~g}^{-1}$ ).

2.4. DPPH Radical Scavenging. Aliquots of the samples $(2.5 \mathrm{~mL})$ were incubated in the absence of light and at room temperature with a 2,2-diphenyl-1-picrylhydrazyl (DPPH) radical solution $(300 \mu \mathrm{M}, 40 \mathrm{~mL})$ for 30 minutes. Thus, absorbance was recorded at $518 \mathrm{~nm}$ in triplicate to check the bleaching of the mixture, indicating the radical scavenging. Ascorbic acid and rutin were used as positive controls, and methanol was used as the negative control [14].

2.5. Phosphomolybdenum Spectrophotometric Method. Aliquots of the plant samples $\left(0.3 \mathrm{~mL}, 200 \mu \mathrm{g} \cdot \mathrm{mL}^{-1}\right)$ in methanol were added to $3 \mathrm{~mL}$ of the phosphomolybdenum reagent and were allocated at $95^{\circ} \mathrm{C}$ during 90 minutes, and then the absorbance was measured at $695 \mathrm{~nm}$ in triplicate. The results were expressed as percentages of antioxidant activity in comparison with ascorbic acid and rutin [15].

2.6. Thiobarbituric Acid Reactive Substances (TBARS). Aliquots of each sample $(100 \mu \mathrm{L}=100 \mathrm{ppm})$ were suspended in ethanol. Further, egg yolk solution $(500 \mu \mathrm{L}), 2,2^{\prime}$-azobis(2amidinopropane)-dihydrochloride (ABAP, $50 \mu \mathrm{L}, 0.035 \%$ ), acetic acid $(1.5 \mathrm{~mL}, 20 \% \mathrm{v} / \mathrm{v})$, and thiobarbituric acid (TBA, $1.5 \mathrm{~mL}, 0.4 \% \mathrm{~m} / \mathrm{v}$ ) were added, and the reaction occurred for 60 minutes at $95^{\circ} \mathrm{C}$. Positive control was butylated hydroxytoluene (BHT). The final reaction mixture was then extracted with $n$-butanol and centrifuged for 3 minutes. The absorbance values of the supernatants were measured at $532 \mathrm{~nm}$ to detect the formation of malondialdehyde (MDA) indicating the decomposition of polyunsaturated fatty acid compounds [16]. The analysis was performed in quintuplicate.

2.7. Phytochemical Analysis. We used a HPLC-MS system, consisting of a Shimadzu SPD-M10 apparatus coupled to a Bruker Amazon ion-trap mass spectrometer. Electrospray ionization (ESI) was used to explore the phenolic composition of $B$. duckeana leaf extract and fractions. Chromatographic separation was performed on a Phenomenex Luna C18 column $(5 \mu \mathrm{m}, 250 \times 4.6 \mathrm{~mm})$ using a binary mobile phase. Solvent A was water and solvent B was methanol. A gradient elution at $30^{\circ} \mathrm{C}$ was performed as follows: 0$3 \mathrm{~min}, 5 \%$ (v/v) B; 3-40 min, 5-70\% (v/v) B; 40-44 min, 70$100 \%(\mathrm{v} / \mathrm{v}) \mathrm{B}$; and $44-60 \mathrm{~min}, 100 \%(\mathrm{v} / \mathrm{v}) \mathrm{B}$, at a flow rate of $0.4 \mathrm{~mL} \cdot \mathrm{min}^{-1}$. The autosampler temperature was held at $20^{\circ} \mathrm{C}$ and the injection volume was $10 \mu \mathrm{L}$. The ESI source operated in negative mode for the identification of the polyphenols [17]. Ionization parameters were as follows: VCap, $3500 \mathrm{~V}$; nozzle voltage, $0 \mathrm{~V}$; fragmentor, $100 \mathrm{~V}$; skimmer, $65 \mathrm{~V}$; gas temperature, $280^{\circ} \mathrm{C}$; gas flow, $14 \mathrm{~L} \mathrm{~min}^{-1}$; and nebulizer, 45 psi. The MS and MS/MS spectra were acquired at the $\mathrm{m} / z$ range from 50 to 1000 . Tentative identifications were 
performed by manual interpretation of MS/MS spectral data with those previously reported [17-19].

2.8. Animals. We performed experiments with male Swiss mice (25-35 g) for the crude EEB and with both sexes, in groups equally balanced, for the comparison between EEB and its respective fractions. The animals were housed in polypropylene cages at $25 \pm 2^{\circ} \mathrm{C}$ with a $12 \mathrm{~h}$ light-dark cycle and acclimatized in the experimental environment for at least $24 \mathrm{~h}$ before the tests. Water and a balanced diet were continually provided ad libitum, but food was withdrawn $12 \mathrm{~h}$ before the tests. All experiments were approved by the Ethics Committee for Animal Research of the Federal University of Amazonas (UFAM, protocol number 048/2011) and Pontifical Catholic University of Paraná (PUC-PR, protocol number 675 , second version).

2.9. Acute Toxicity. A maximum dosage of $2000 \mathrm{mg} \cdot \mathrm{kg}^{-1}$ of the samples studied in this work was dissolved in normal saline solution and administered orally to different groups with each consisting of eight mice. Abnormal morphological and behavioral signs of toxicity were evaluated during the first $4 \mathrm{~h}$ after administration of $B$. duckeana samples [20] and at $24 \mathrm{~h}$ intervals, for 14 days [21]. For the negative control group only saline solution was administered.

2.10. Formalin-Induced Pain Test. Four groups of eight mice each received $20 \mu \mathrm{L}$ of a formalin solution $(2.5 \%, \mathrm{v} / \mathrm{v})$ by intraplantar injections into the ventral surface of the right hind paw. One hour before injections, two groups received EEB at 500 and $1000 \mathrm{mg} \cdot \mathrm{kg}^{-1}$, orally. The total time spent by each mouse on licking its paw was recorded with a hand chronometer. The animals were observed for 30 minutes, according to each phase of the test: neurogenic ( $0-5$ minutes) and inflammatory phases (15-30 minutes), respectively. At the end of the test, the animals were euthanized and the inflamed paws were sectioned and weighed to measure the formed edema. Morphine at $3 \mathrm{mg} \cdot \mathrm{kg}^{-1}$ and the saline solution were used as positive and negative controls, respectively [22, 23].

2.11. Carrageenan-Induced Peritonitis Test. Three groups of eight mice received injections of $250 \mu \mathrm{L}$ of carrageenan in normal saline solution $(1 \%, \mathrm{v} / \mathrm{v})$ into the peritoneum. Two of the groups previously received EEB at 500 and $1000 \mathrm{mg} \cdot \mathrm{kg}^{-1}$ by the oral route. Four hours after the carrageenan injection, the mice were euthanized by an intraperitoneal injection of a mixture of xylazine $\left(350 \mathrm{mg} \cdot \mathrm{mL}^{-1}\right)$ and ketamine $\left(40 \mathrm{mg} \cdot \mathrm{mL}^{-1}\right)$. After the euthanasia of animals, the peritoneal cavity was washed with $2 \mathrm{~mL}$ of phosphate buffer saline (PBS); then, the collected peritoneal fluid was centrifuged at $3000 \mathrm{rpm}$ for 10 minutes. The supernatant was used to determine the total amount of proteins in the exudate, by measuring the absorbance at $280 \mathrm{~nm}$. The cell pellets were diluted in a mixture sodium phosphate buffer and Turk solution $(1: 10, \mathrm{v} / \mathrm{v})$ and used for the total leukocyte counting [24].
2.12. Acetic Acid-Induced Writhing Test. Six groups of six mice each were used for this experiment. Four different groups received fraction samples, being $100 \mathrm{mg} \cdot \mathrm{kg}^{-1}$ of each fraction to one group (EEB, FHX, FCL, and FEA) by oral administration. The positive control group received indomethacin at a dosage of $10 \mathrm{mg} \cdot \mathrm{kg}^{-1}$, and the negative control group received the normal saline solution. After 60 minutes, all mice received an intraperitoneal injection of an acetic acid solution ( $1 \%, \mathrm{v} / \mathrm{v}$ in saline solution). The abdominal writhings were counted cumulatively during 20 minutes after the injection, and the total cumulative number in this period was taken as an indicator of the nociceptive response [25].

2.13. Hot Plate Test. Different groups of the six mice received dosages of 5,50 , and $200 \mathrm{mg} \cdot \mathrm{kg}^{-1}$ of FEA orally. Other two groups received $10 \mathrm{mg} \cdot \mathrm{kg}^{-1}$ of indomethacin (positive control) and normal saline solution (negative control). The animals were placed individually on a digital hot plate (Insight EFF-361) previously heated to $52 \pm 2^{\circ} \mathrm{C}$, and the typical behavior was observed at time 0 (to obtain a baseline) and at $30,60,90$, and 120 minutes after the fraction administration [21].

2.14. Statistical Analysis. The results were presented as mean \pm standard deviation when applicable. Since no difference was observed in the response of female or male animals, both sexes were considered in the statistical analysis between the groups. The results of each group in the in vivo analysis were compared by the Tukey test, considering $(p<$ $0.05)$ values as statistically significant. The median inhibitory concentrations $\left(\mathrm{IC}_{50}\right)$ of antioxidant activity were calculated by using linear regression. The statistical analysis was carried out with GraphPad Prism 5.0 Software (GraphPad Software, Inc. La Jolla, USA).

\section{Results}

3.1. Total Phenolics and Antioxidant Capacity. Within the analyzed samples in this study, FEA presented the highest amount of total polyphenols. In the DPPH test, all results presented statistically significant differences $(p<0.05)$ and FCL and FEA showed the best antioxidant capacity of the tested samples. In the phosphomolybdenum test, the same fractions were also the most active samples, but FEA and rutin showed no statistical difference between the obtained results, indicating that they are equivalent. In the evaluation of inhibition of the lipid peroxidation (TBARS), FEA presented the highest inhibitory potential of all tested samples (Table 1).

3.2. Phytochemical Analysis. The EEB extract was analyzed by LC-MS/MS and direct infusion electrospray ionization tandem mass spectrometry (DI-ESI-MS/MS) (Figure 1). Fractions FCL and FEA were analyzed only by DI-ESI-MS/MS due to the low complexity observed for their corresponding extracts. 
TABLE 1: Phenol content and antioxidant activity of Byrsonima duckeana.

\begin{tabular}{|c|c|c|c|c|}
\hline Samples & Total phenols* (EqGA/g) & $\mathrm{DPPH}\left(\mathrm{IC}_{50}\right.$ in $\left.\mu \pm \sigma \mu \mathrm{g} / \mathrm{mL}\right)$ & PES (\% of AA) & TBARS (\% inhibition of lipid peroxidation) \\
\hline Ethanolic extract & 466.60 & $14.88 \pm 0.04$ & $38.15 \pm 0.00$ & $76.95 \pm 0.01$ \\
\hline Hexane fraction & 108.84 & $38.51 \pm 0.09$ & $24.20 \pm 0.00$ & $70.57 \pm 0.02$ \\
\hline Chloroform fraction & 582.46 & $6.24 \pm 0.02$ & $60.29 \pm 0.01$ & $74.79 \pm 0.02$ \\
\hline Ethyl acetate fraction & 743.74 & $8.22 \pm 0.04$ & $42.46 \pm 0.00$ & $88.69 \pm 0.01$ \\
\hline Ascorbic acid & NT & $4.60 \pm 0.14$ & 100 & NT \\
\hline Rutin & NT & $6.01 \pm 0.01$ & $40.94 \pm 0.01$ & NT \\
\hline BHT & NT & NT & NT & $21.54 \pm 0.02$ \\
\hline
\end{tabular}

NT: not tested; ${ }^{*}$ data shown in gallic acid equivalents.

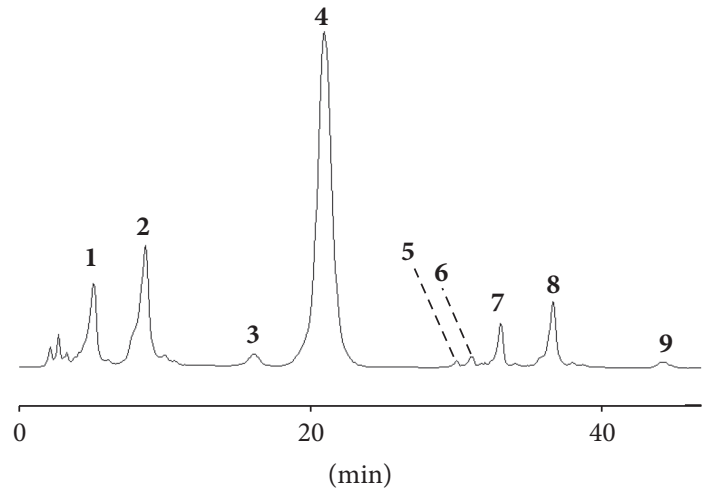

FIGURE 1: UHPLC-MS/MS chromatogram of the ethanolic extract of $B$. duckeana (EEB) showing the following compounds: quinic acid (1), gallic acid (2), unknown (3), ethyl gallate (4), catechin (5), epicatechin (6), quercetrin (7), quercetin (8), and unknown (9).

The deprotonated ions $[\mathrm{M}-\mathrm{H}]^{-}$and their corresponding fragments from CID experiments were compared to fragmentation routes previously described [18]. For the analysis of $\mathrm{EEB}$, the peak eluting at $5.71 \mathrm{~min}$ displayed the deprotonated molecule at $\mathrm{m} / \mathrm{z} 191$, which fragments to the ion of $\mathrm{m} / \mathrm{z}$ 173 (-18 Da; neutral loss of water) and $m / z 127(-46 \mathrm{Da}$; neutral loss of formic acid), allowing to identify it as quinic acid. Further product ions at $m / z$ 111, 93, and 85 reinforced this structure proposal [25]. Peak $2\left(R_{t} 9.53 \mathrm{~min}\right)$ was tentatively identified as the gallic acid based on its deprotonated molecule at $m / z 169$ and the characteristic carbon dioxide loss $(-44 \mathrm{Da})$, giving the fragment $\left[\mathrm{M}-\mathrm{CO}_{2}-\mathrm{H}\right]^{-}$at $m / z 125$ [26]. The main peak (4), eluting at $20.37 \mathrm{~min}$, was tentatively assigned as ethyl gallate based on its typical fragmentation ions $(\mathrm{m} / z 197 \rightarrow 169$ and $\mathrm{m} / z 169 \rightarrow 125)$, related to those observed for the gallic acid [17].

Peaks 5 and $\mathbf{6}$ eluted at 29.84 and $30.63 \mathrm{~min}$, respectively. Both peaks displayed the same MS/MS spectra, where the deprotonated ion $(\mathrm{m} / \mathrm{z} 289)$ displayed CID fragments consistent with those reported for the catechins. Based on the product ion and on the elution order previously reported, peaks 5 and 6 were assigned as (+)-catechin and (-)epicatechin, respectively [19]. The compound that eluted at $33.09 \mathrm{~min}$ (peak 7) displayed a deprotonated ion at $\mathrm{m} / \mathrm{z} 447$, with a glucose loss as first fragmentation $(-162 \mathrm{Da})$, yielding the product ion at $\mathrm{m} / \mathrm{z} 301$. This and the other corresponding fragments are in accordance with the tentative identification of quercetrin for this peak elution. Its corresponding aglycone was observed eluting at $36.15 \mathrm{~min}$ (peak 8) [27]. The less intense peaks 3 and $\mathbf{9}$ displayed uncommon fragmentation behaviors, being both assigned as unknown compounds.

Phenolic acids and esters and some flavonoids were identified in the two most promising fractions FCL and FEA. The main compounds of FCL were quinic acid, gallic acid, and ethyl gallate. In minor proportions, catechin, quercetin and quercetrin were observed. Ethyl gallate was the main compound of FEA (Figure 2).

3.3. Acute Toxicity. The toxicity of the EEB sample was analyzed. No deaths in the groups of animals that received EEB at the maximum dosage were observed and no macroscopic signs of harmful effects were observed in any of the animals; thus, the $\mathrm{LD}_{50}$ was not calculated.

3.4. Formalin-Induced Pain Test. In this assay, EEB inhibited the inflammatory phase (15-30 minutes) and the neurogenic one (0-5 minutes) in the dosage of $1000 \mathrm{mg} \cdot \mathrm{kg}^{-1}$ (Figure 3).

3.5. Carrageenan-Induced Peritonitis Test. The number of leukocytes that migrated to the site of the inflammation local was $45.25 \pm 9.84 \%$ lower than in the negative controls, at the dosage of $500 \mathrm{mg} \mathrm{kg}^{-1}$ of EEB, and $51.95 \pm 5.94 \%$ lower at the dose of $1000 \mathrm{mg} \cdot \mathrm{kg}^{-1}$, without statistical differences between them. The protein exudation was lowered by $12.79 \pm$ $2.61 \%$ and $45.38 \pm 8.55 \%$ for both dosages, respectively $(p<$ $0.05)$. This previous analysis showed that the activity of EEB reduced the leucocyte migration, suggesting that extract may control the symptoms of the acute inflammation; however, only the dosage of $1000 \mathrm{mg} \cdot \mathrm{kg}^{-1}$ interfered significantly with protein exudation.

3.6. Acetic Acid-Induced Writhing Test. To perform the screening of samples in the writhing test, a dosage of $100 \mathrm{mg} \cdot \mathrm{kg}^{-1}$, commonly used in in vivo pharmacological assays of crude plant extracts and prepurified fractions were selected. The analysis of variance between the mean counts of abdominal writhings in each group showed that EEB, FCL, and FEA present statistically significant analgesic activity $(p<0.05)$ in comparison with the negative control (normal saline) (Figure 4). 
<smiles>O=C(O)[C@]1(O)C[C@@H](O)[C@H](O)[C@H](O)C1</smiles>

1<smiles>O=C(O)c1cc(O)c(O)c(O)c1</smiles>

2<smiles>CCOC(=O)c1cc(O)c(O)c(O)c1</smiles>

4<smiles>Oc1cc(O)c2c(c1)O[C@H](c1ccc(O)c(O)c1)[C@H](O)C2</smiles>

5<smiles>O=c1c(O[C@@H]2C(O)[C@H](O)[C@H](O)C(O)[C@H]2O)c(-c2ccc(O)c(O)c2)oc2cc(O)cc(O)c12</smiles><smiles>Oc1cc(O)c2c(c1)O[C@H](c1ccc(O)c(O)c1)[C@H](O)C2</smiles>

6

Figure 2: Polyphenols identified in B. duckeana.
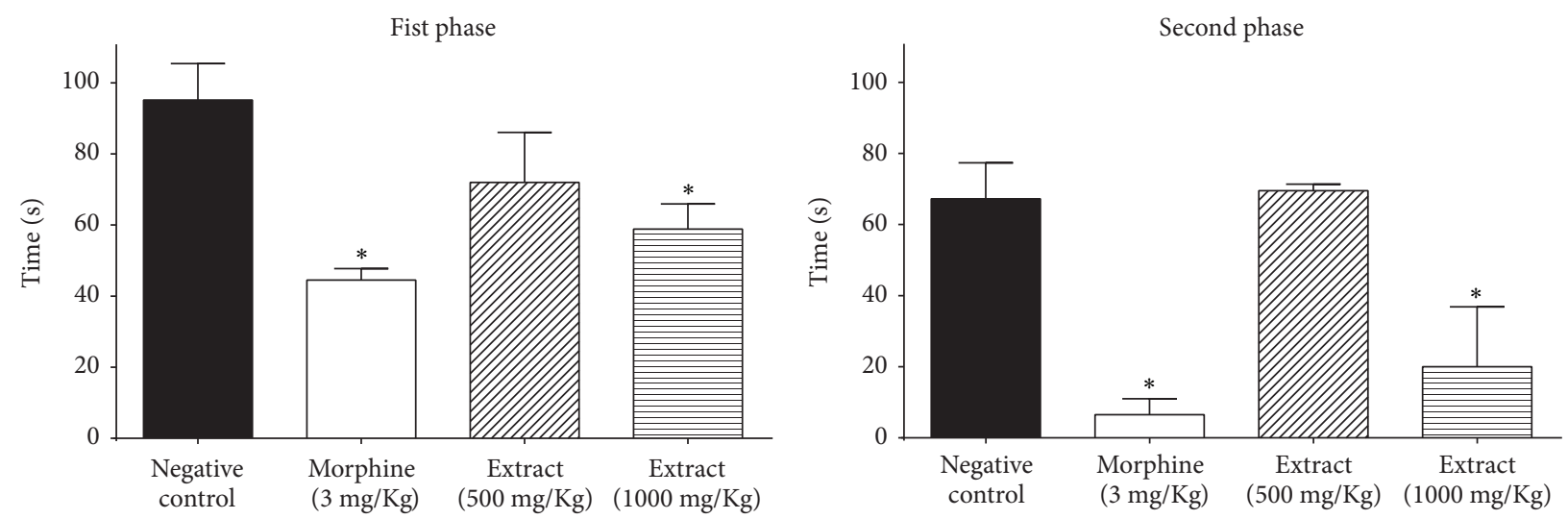

Figure 3: Results of the preliminary screening of analgesic potential of Byrsonima duckeana. ${ }^{*} p<0.05$ versus negative control.

3.7. Hot Plate Test. For the hot plate test, only FEA was administrated to the mice $\left(5,50\right.$, and $\left.200 \mathrm{mg} \cdot \mathrm{kg}^{-1}\right)$. FEA at a dosage of $200 \mathrm{mg} \cdot \mathrm{kg}^{-1}$ showed significant activity when compared with the negative control for all analyzed periods.
At 90 and 120 minutes, all tested dosages showed analgesic activity. None of them showed differences in comparison with positive control (indomethacin $10 \mathrm{mg} \cdot \mathrm{kg}^{-1}$ ). FEA showed antinociceptive activity equivalent to that of the standard 


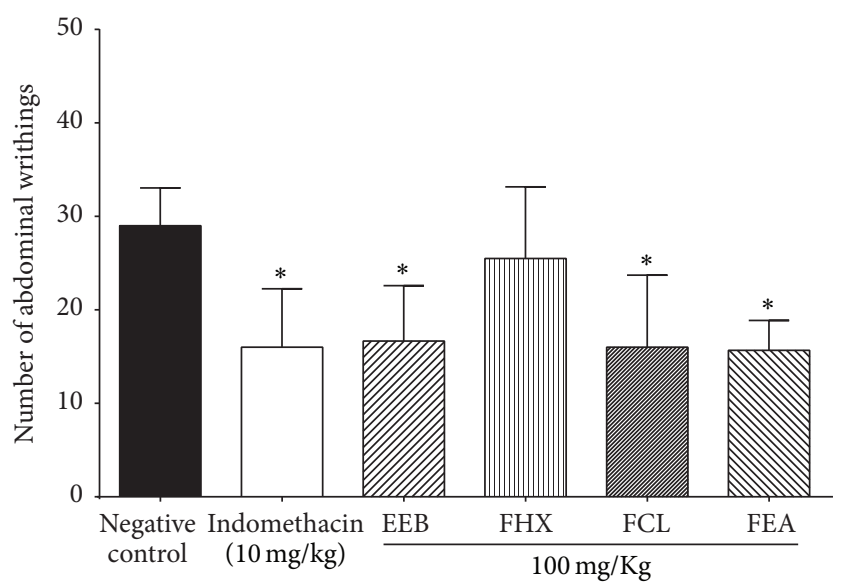

FIGURE 4: Effect of crude extract and fractions of Byrsonima duckeana on acetic acid-induced abdominal writhing. EEB: crude ethanolic extract. FEA: ethyl acetate fraction. FCL: chloroform fraction. FHX: hexane fraction. ${ }^{*} p<0.05$ versus negative control.

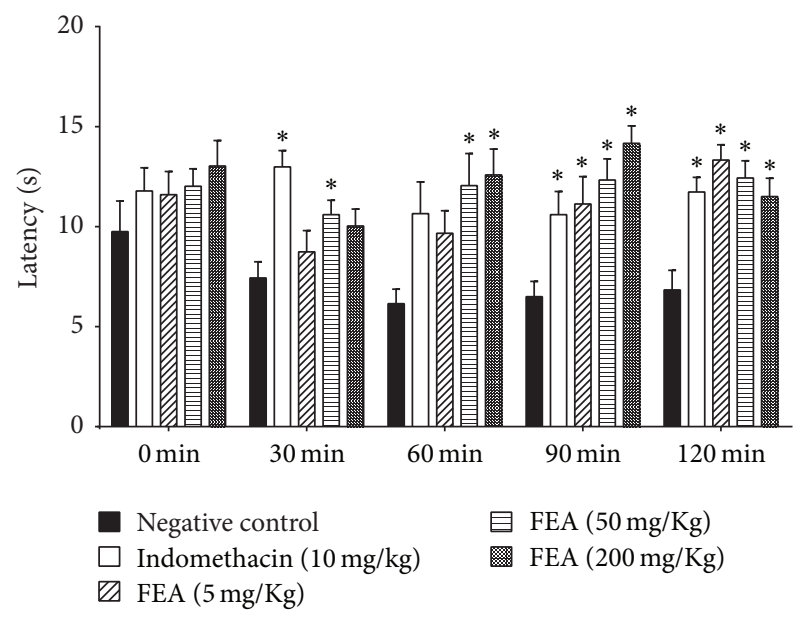

FIGURE 5: Effect of ethyl acetate fraction (FEA) of Byrsonima duckeana on the hot plate test. Maximal activity of all the dosages was observed at 90 minutes. ${ }^{*} p<0.05$ versus negative control.

drug, even at the lowest dosage tested, $5 \mathrm{mg} \cdot \mathrm{kg}^{-1}$, half of the dose positive control, revealing FEA, as a promising source of substances with analgesic activity (Figure 5).

\section{Discussion}

In this study, which aimed to investigate the pharmacological potentials of $B$. duckeana, an evaluation of its antiinflammatory, analgesic, and antioxidant abilities was carried out, considering the empirical medicinal use of plants of this genus.

Since polyphenols are considered the most active antioxidant metabolites from plants, the relationship between polyphenol concentration and antioxidant activity has been the focus of many studies $[28,29]$. The mass spectrometry analysis highlighted that the phenolic constitution of FEA is mainly composed of traces of gallic acid in association with high amounts of its corresponding ethyl ester. These results are in agreement with the observed anti-inflammatory actions of FEA, once antioxidant compounds like phenol acids and esters can inhibit the formation of peroxynitrite $\left(\mathrm{ONOO}^{-}\right)$from the combination of superoxide radical $\left(\mathrm{O}_{2}{ }^{-\bullet}\right)$ and nitric oxide $(\mathrm{NO})$ released during the inflammatory response (membrane damage, lipid peroxidation) [11]. These reactive oxygen species (ROS) have been implicated in the pathogenesis of various diseases, including rheumatoid arthritis, asthma, atherosclerosis, and Alzheimer's disease and, furthermore, critically involved in various pain conditions, including neuropathic and inflammatory pains [30]. These ROS are also involved in the promotion of the induction of hyperalgesia by prostaglandin E2 [31].

In the acute toxicity analysis, because of no toxicity at the doses tested, we assume that EEB only causes toxicity at higher dosages than those tested, indicating that the crude ethanolic extract is safe for administration through the oral route. These results reinforce previous observations that Byrsonima spp are safe for in vivo studies [9]. Based on this result, dosages of 500 and $1000 \mathrm{mg} \cdot \mathrm{kg}^{-1}$ were selected for the preliminary investigation of the anti-inflammatory/antihyperalgesic screening using the carrageenan-induced peritonitis model and the formalin test.

The inflammatory response in a carrageenan-induced pleurisy culminates in exudation and leukocyte infiltration, which release chemical mediators responsible for the cardinal signals of inflammation, namely, edema, pain, heat, redness, and loss of function [32]. It is clear that protein exudation is more closely related to edema than to other events [33]. These chemical mediators released by the leucocytes and other recruited cells are responsible, for example, for the hypersensitization of nerve fibers, which cause inflammatory pain or hyperalgesia [34]. This previous analysis showed that the activity of EEB reduced leucocyte migration, suggesting that the extract may control the symptoms of acute inflammation; however, only the dosage of $1000 \mathrm{mg} \cdot \mathrm{kg}^{-1}$ interfered significantly with protein exudation.

In order to evaluate the action of EEB in an acute inflammation model, we deployed the formalin test, which is a satisfactory model for evaluating the anti-inflammatory/ antinociceptive activity of plant extracts and isolated molecules. In the first phase of the test, intraplantar injections of formalin produce neurogenic pain, which combines a peripheral input and a spinal cord sensitization [32]. This phase is associated with an acute pain that starts immediately after the injection and involves nociceptors. The second phase is an inflammatory pain response inhibited by traditional analgesic and anti-inflammatory drugs [35].

Based on such observations, EEB presented antihyperalgesic capacity, but without statistical difference in comparison with the positive control (morphine $3 \mathrm{mg} \cdot \mathrm{kg}^{-1}$ ). On the other hand, it was observed that none of the EEB amounts significantly reduced the edema in this test, as determined by weighting the paws, which is in agreement with the results observed in carrageenan-induced peritonitis model. In order to better investigate the analgesic action of $B$. duckeana, EEB 
and its respective fractions were evaluated by an abdominal writhing test.

Abdominal writhings in mice are characterized by abdominal contractions and rotations, followed by the extension of one or both hind legs. Acetic acid is a convenient stimulus for screening tests as it produces a response whose intensity depends on the interaction of many events that determine the nociception and is sensitive to analgesic substances of central and/or peripheral action, with different mechanisms of action [21].

In the writhing test, no differences were found in comparison with the positive control and, thus, it is possible to assume that the activities were equivalent. The results of this test showed that compounds with medium polarity (FCL and FEA) are more directly related to the analgesic activity of EEB. Thus, FEA was selected for the hot plate test in order to investigate if its analgesic activity is due to central action of its compounds, as previously suggested in formalin test.

Hot plate test is a central model of nociception, which is based on a high-intensity phasic stimulus [36]. Two behavioral responses are observed in this test, paw licking and jumping, being both considered supraspinally integrated responses and the timing of the latency to the onset of this response after administration is an indicative of the analgesic activity [34].

Thus, it is possible to infer that the antioxidant potential of B. duckeana may be related to the anti-inflammatory activity, and in particular, to the antihyperalgesic activity observed. The hot plate test, in which $B$. duckeana displayed positive results, is a classic model for the evaluation of antinociceptive activity. In this case, the mechanism of this activity requires further investigation, although there is evidence that ROS are also involved in the mechanism of the nociceptive pain [37].

\section{Conclusion}

This investigation displayed the pharmacological potential of $B$. duckeana, one of the few Amazonian native species of Byrsonima scientifically studied. The results indicate that this species has a promising analgesic activity, appearing to have action in both hyperalgesic and nociceptive pain, which requires further investigation in order to better explain their mechanism of action. Nevertheless, the observed effects may be related to polyphenols, abundant in the extract and respective fractions. The ethyl acetate fraction displayed strong antioxidant capacity, including free radical scavenging and inhibition of lipid peroxidation, which may lead to the improvement of pain relief. Furthermore, the chemical investigation using the ethyl acetate fraction showed that ethyl gallate is a major constituent, which can explain strong antioxidant activity observed. Furthermore, the species have also shown an interesting phenolic composition, including quercitrin, which has been identified in Byrsonima specie for first time.

\section{Competing Interests}

The authors declare that they do not have conflict of interests.

\section{Acknowledgments}

The authors acknowledge Fundação de Amparo à Pesquisa do Estado do Amazonas (FAPEAM) for financial support to this study.

\section{References}

[1] E. Cadirci, Z. Halici, M. Yayla et al., "Blocking of urotensin receptors as new target for treatment of carrageenan induced inflammation in rats," Peptides, vol. 82, pp. 35-43, 2016.

[2] D. T. Longhi-Balbinot, D. Lanznaster, C. H. Baggio et al., "Antiinflammatory effect of triterpene $3 \beta, 6 \beta, 16 \beta$-trihydroxylup20(29)-ene obtained from Combretum leprosum Mart \& Eich in mice," Journal of Ethnopharmacology, vol. 142, no. 1, pp. 59-64, 2012.

[3] P. A. Batista, M. F. De Paula Werner, E. C. Oliveira et al., "The antinociceptive effect of (-)-linalool in models of chronic inflammatory and neuropathic hypersensitivity in mice," Journal of Pain, vol. 11, no. 11, pp. 1222-1229, 2010.

[4] L. F. Ruviaro and L. I. Filippin, "Prevalence of chronic pain in a Basic Health Unit of a middle-sized city," Revista Dor, vol. 13, no. 2, pp. 128-131, 2012.

[5] D. F. Martins, B. L. Turnes, F. J. Cidral-Filho et al., "Lightemitting diode therapy reduces persistent inflammatory pain: role of interleukin 10 and antioxidant enzymes," Neuroscience, vol. 324, pp. 485-495, 2016.

[6] N. B. Finnerup, N. Attal, S. Haroutounian et al., "Pharmacotherapy for neuropathic pain in adults: a systematic review and meta-analysis," The Lancet Neurology, vol. 14, no. 2, pp. 162-173, 2015.

[7] L. C. Neves, P. M. C. da Silva, C. G. B. Lima, V. J. Bastos, and S. R. Roberto, "Study to determine the optimum harvest date of Murici (Byrsonima coccolobifolia Kunth.) from quality and functional attributes," Scientia Horticulturae, vol. 188, pp. 4956, 2015.

[8] C. Z. D. R. Barbosa, M. S. de Mendonça, and R. S. Rodrigues, "Seedling morphology of three sympatric savanna species of Byrsonima: first evidence of cryptogeal germination in Malpighiaceae and an overlooked seedling type in eudicots," Flora: Morphology, Distribution, Functional Ecology of Plants, vol. 209, no. 8, pp. 401-407, 2014.

[9] F. Guilhon-Simplicio and M. De Meneses Pereira, "Chemical and pharmacological aspects of Byrsonima (Malpighiaceae)," Quimica Nova, vol. 34, no. 6, pp. 1032-1041, 2011.

[10] M. C. Dos Santos Verdam, F. Guilhon-Simplicio, C. Da Silva Paula et al., "Cytotoxicity of Byrsonima duckeana W. R. Anderson (malpighiaceae) on colon cancer cells," International Journal of Pharmacy and Pharmaceutical Sciences, vol. 6, no. 11, pp. 509-510, 2014.

[11] F. Guilhon-Simplicio, C. C. D. S. Pinheiro, G. G. Conrado et al., "Anti-inflammatory, anti-hyperalgesic, antiplatelet and antiulcer activities of Byrsonima japurensis A. Juss. (Malpighiaceae)," Journal of Ethnopharmacology, vol. 140, no. 2, pp. 282-286, 2012.

[12] J. E. L. S. Ribeiro, M. J. G. Hopkins, A. Vicentini et al., Flora da Reserva Ducke. Guia de Identificação das Plantas Vasculares de Uma Floresta de Terra Firme na Amazônia Central, INPA-DFID, Manaus, Brazil, 1999.

[13] O. N. Pozharitskaya, A. N. Shikov, M. N. Makarova et al., "Anti-inflammatory activity of a HPLC-fingerprinted aqueous infusion of aerial part of Bidens tripartita L," Phytomedicine, vol. 17, no. 6, pp. 463-468, 2010. 
[14] L. L. Mensor, F. S. Menezes, G. G. Leitão et al., "Screening of Brazilian plant extracts for antioxidant activity by the use of DPPH free radical method," Phytotherapy Research, vol. 15, no. 2, pp. 127-130, 2001.

[15] P. Prieto, M. Pineda, and M. Aguilar, "Spectrophotometric quantitation of antioxidant capacity through the formation of a phosphomolybdenum complex: specific application to the determination of vitamin E," Analytical Biochemistry, vol. 269, no. 2, pp. 337-341, 1999.

[16] C. A. de Andrade, J. L. D. S. Carvalho, M. M. Cunico et al., "Antioxidant and antibacterial activity of extracts, fractions and isolated substances from the flowers of Acacia podalyriifolia A. Cunn. ex G. Don," Brazilian Journal of Pharmaceutical Sciences, vol. 46, no. 4, pp. 715-721, 2010.

[17] G. A. Bataglion, F. M. A. Da Silva, M. N. Eberlin, and H. H. F. Koolen, "Determination of the phenolic composition from Brazilian tropical fruits by UHPLC-MS/MS," Food Chemistry, vol. 180, pp. 280-287, 2015.

[18] N. Fabre, I. Rustan, E. De Hoffmann, and J. Quetin-Leclercq, "Determination of flavone, flavonol, and flavanone aglycones by negative ion liquid chromatography electrospray ion trap mass spectrometry," Journal of the American Society for Mass Spectrometry, vol. 12, no. 6, pp. 707-715, 2001.

[19] G. A. Bataglion, F. M. A. da Silva, J. M. Santos et al., "Comprehensive characterization of lipids from Amazonian vegetable oils by mass spectrometry techniques," Food Research International, vol. 64, pp. 472-481, 2014.

[20] M. H. Malone and R. C. Robichaud, "A hippocratic screen for pure or crude drug materials," Lloydia, vol. 25, no. 4, pp. 320332, 1962.

[21] A. J. Lapa, A. C. Souccar, M. T. R. Lima-Landaman, M. S. A. Castro, and T. C. M. De Lima, Plantas Medicinais: Métodos de Avaliação da Atividade Farmacológica, UNIFESP/EPM, Campinas, Brazil, 2008.

[22] A. R. S. Santos and J. B. Calixto, "Further evidence for the involvement of tachykinin receptor subtypes in formalin, and capsaicin models of pain in mice," Neuropeptides, vol. 31, no. 4, pp. 381-389, 1997.

[23] A. Beirith, A. R. S. Santos, J. B. Calixto et al., "Study of the antinociceptive action of the ethanolic extract and the triterpene 24-hydroxytormentic acid isolated from the stem bark of Ocotea suaveolens," Planta Medica, vol. 65, no. 1, pp. 5055, 1999.

[24] A. Bose, S. Mondal, J. K. Gupta, T. Ghosh, G. K. Dash, and S. $\mathrm{Si}$, "Analgesic, anti-inflammatory and antipyretic activities of the ethanolic extract and its fractions of Cleome rutidosperma," Fitoterapia, vol. 78, no. 7-8, pp. 515-520, 2007.

[25] L. C. Bastos, E. A. de Almeida Costa, and P. A. Pereira, "Development, validation and application of an UFLC-DADESI-MS method for determination of carbonyl compounds in soybean oil during continuous heating," Food Chemistry, vol. 218, pp. 518-524, 2017.

[26] P. Quifer-Rada, A. Vallverdú-Queralt, M. Martínez-Huélamo et al., "A comprehensive characterisation of beer polyphenols by high resolution mass spectrometry (LC-ESI-LTQ-OrbitrapMS)," Food Chemistry, vol. 169, pp. 336-343, 2015.

[27] H. H. F. Koolen, F. M. A. da Silva, F. C. Gozzo, A. Q. L. de Souza, and A. D. L. de Souza, "Antioxidant, antimicrobial activities and characterization of phenolic compounds from buriti (Mauritia flexuosa L. f.) by UPLC-ESI-MS/MS," Food Research International, vol. 51, no. 2, pp. 467-473, 2013.
[28] E. Köksal, E. Bursal, İ. Gülçin et al., "Antioxidant activity and polyphenol content of Turkish thyme (Thymus vulgaris) monitored by liquid chromatography and tandem mass spectrometry," International Journal of Food Properties, pp. 1-12, 2016.

[29] M. P. de Souza, G. A. Bataglion, F. M. A. da Silva et al., "Phenolic and aroma compositions of pitomba fruit (Talisia esculenta Radlk.) assessed by LC-MS/MS and HS-SPME/GC-MS," Food Research International, vol. 83, pp. 87-94, 2016.

[30] H. Y. Kim, I. Lee, S. W. Chun, and H. K. Kim, "Reactive oxygen species donors increase the responsiveness of dorsal horn neurons and induce mechanical hyperalgesia in rats," Neural Plasticity, vol. 2015, Article ID 293423, 10 pages, 2015.

[31] M. M. Ndengele, S. Cuzzocrea, E. Esposito et al., "Cyclooxygenases 1 and 2 contribute to peroxynitrite-mediated inflammatory pain hypersensitivity," FASEB Journal, vol. 22, no. 9, pp. 3154-3164, 2008.

[32] D. K. S. Lima, L. J. Ballico, F. Rocha Lapa et al., "Evaluation of the antinociceptive, anti-inflammatory and gastric antiulcer activities of the essential oil from Piper aleyreanum C.DC in rodents," Journal of Ethnopharmacology, vol. 142, no. 1, pp. 274282, 2012.

[33] I. Francischetti, J. B. Moreno, M. Scholz, and W. B. Yoshida, "Os leucócitos e a resposta inflamatória na lesão de isquemiareperfusão," Brazilian Journal of Cardiovascular Surgery, vol. 25, no. 4, pp. 575-584, 2010.

[34] L. Orlandi, F. C. Vilela, F. V. Santa-Cecília, D. F. Dias, G. Alves-Da-Silva, and A. Giusti-Paiva, "Anti-inflammatory and antinociceptive effects of the stem bark of Byrsonima intermedia A. Juss.", Journal of Ethnopharmacology, vol. 137, no. 3, pp. 14691476, 2011.

[35] L. Wen, Y. Huang, X. Xie et al., "Anti-inflammatory and antinociceptive activities of bufalin in rodents," Mediators of Inflammation, vol. 2014, Article ID 171839, 9 pages, 2014.

[36] C. Velázquez-González, R. Cariño-Cortés, J. A. Gayosso de Lucio et al., "Antinociceptive and anti-inflammatory activities of Geranium bellum and its isolated compounds," BMC Complementary and Alternative Medicine, vol. 14, no. 1, article 506, 2014.

[37] G. Trevisan, C. Hoffmeister, M. F. Rossato et al., "TRPA1 receptor stimulation by hydrogen peroxide is critical to trigger hyperalgesia and inflammation in a model of acute gout," Free Radical Biology and Medicine, vol. 72, pp. 200-209, 2014. 

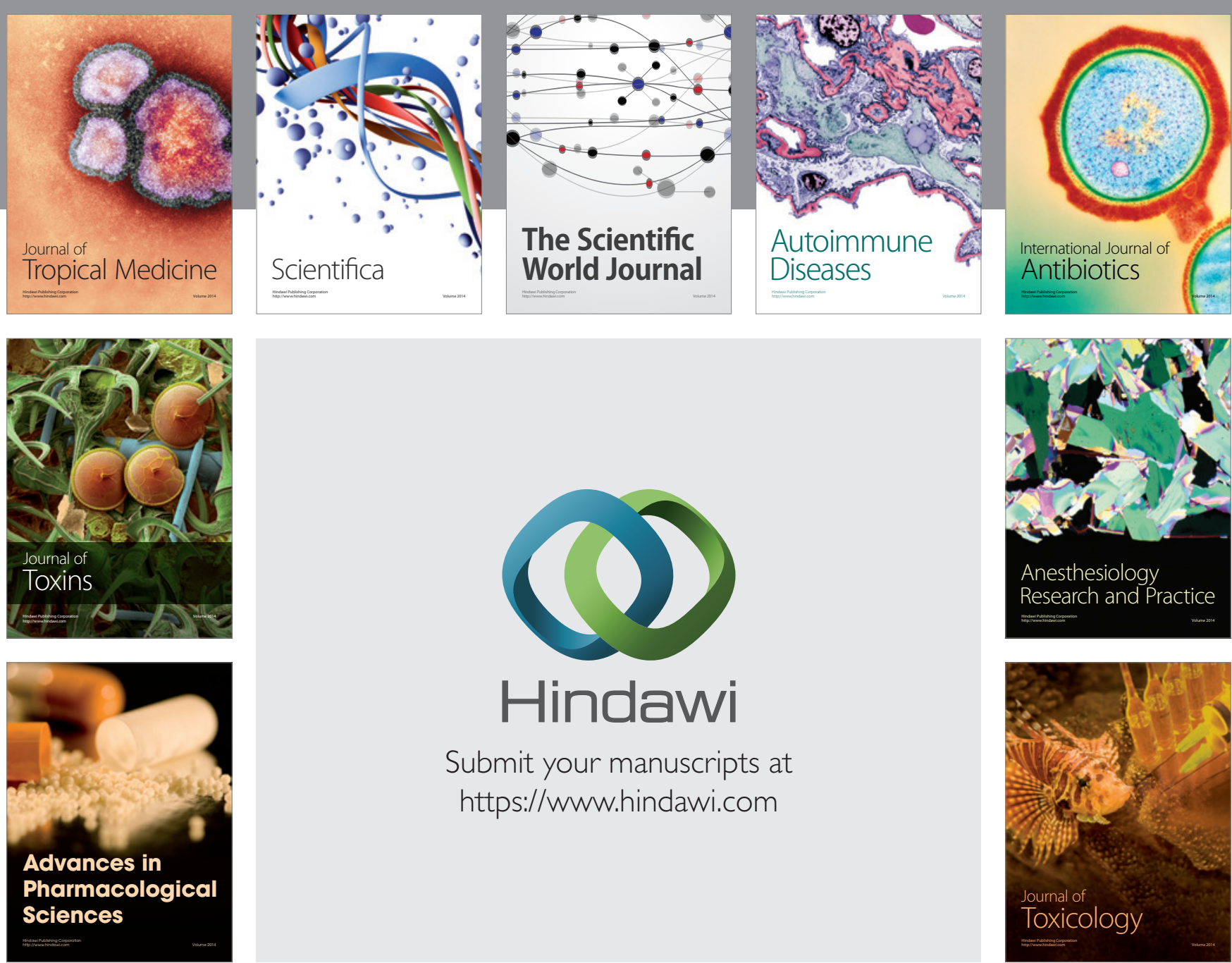

\section{Hindawi}

Submit your manuscripts at

https://www.hindawi.com
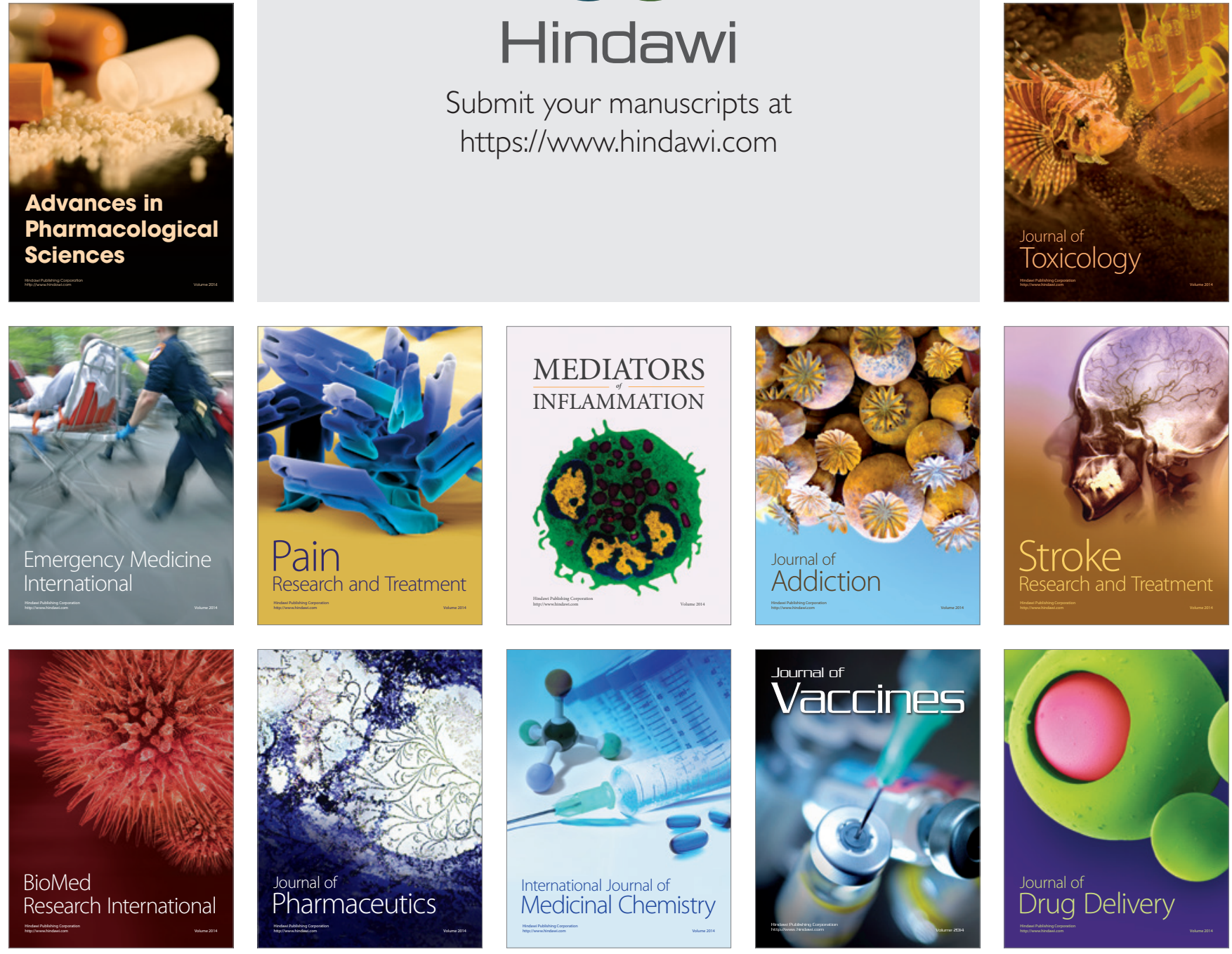